\title{
A construção da didática no GT Didática - análise de seus referenciais*
}

\author{
SELMA GARRIDO PIMENTA \\ Universidade de São Paulo \\ JOSÉ CERCHI FUSARI \\ Universidade de São Paulo \\ MARIA ISABEL DE ALMEIDA \\ Universidade de São Paulo \\ MARIA AMÉLIA DO ROSÁRIO \\ SANTORO FRANCO \\ Universidade Católica de Santos
}

\section{DIDÁTICA: DISPERSÃO EPISTEMOLÓGICA E/OU VARIAÇÕES EM TORNO DE UM OBJETO COMPLEXO?}

Há 355 anos, Comênio convidava os educadores a pensar na questão educacional, propondo a utopia da criação de um método que fosse capaz de ensinar tudo a todos, especialmente o domínio da leitura e da escrita, base para a compreensão e interpretação dos textos bíblicos. Nascia assim a didática, no cerne de uma verdadeira revolução social e política, contra a hegemonia do poder do clero católico na condução do destino da humanidade. Dependendo das circuns-

\footnotetext{
* Trabalho encomendado e apresentado no Grupo de Trabalho Didática (GT-04), na Reunião Anual da Associação Nacional de Pós-Graduação e Pesquisa em Educação (ANPEd), em 2010.
} 
tâncias e do momento histórico, a didática pode ser considerada como a ciência do ensino, a arte do ensino, uma teoria da instrução, uma teoria da formação ou mesmo uma tecnologia para dar suporte metodológico às disciplinas curriculares. De alguma forma, esteve sempre ligada às questões postas pelos processos de ensino, compreendidos como instrumentos de poder, a serviço de interesses diferentes e contraditórias finalidades.

Sabe-se que as formas de concretização do processo de ensino variam no tempo e no espaço, criam-se e recriam-se produzindo modelos e estruturas que caracterizam cada momento histórico. Ao focar o ensino como seu objeto de estudo, a didática precisou construir formas de compreender e dialogar com as circunstâncias que foram e estão se configurando a cada instante.

O ensino é uma prática social complexa. Realizado por seres humanos entre seres humanos, o ensino é transformado pela ação e relação entre os sujeitos (professores e estudantes) situados em contextos diversos: institucionais, culturais, espaciais, temporais, sociais. Por sua vez, dialeticamente, transforma os sujeitos envolvidos nesse processo (Pimenta, 2010). Sendo uma área da pedagogia, a didática tem no ensino seu objeto de investigação. Considerá-lo como uma prática educacional em situações historicamente situadas significa examiná-lo nos contextos sociais nos quais se efetiva - nas aulas e demais situações de ensino das diferentes áreas do conhecimento, nas escolas, nos sistemas de ensino, nas culturas, nas sociedades -, estabelecendo-se os nexos entre tais contextos. Suas novas possibilidades estão emergindo das investigações sobre o ensino como prática social viva (idem). Lembrando sempre que, como realça Contreras (1990, p. 17, tradução nossa),

O ensino não é prática orientada pela didática, o que lhe daria um caráter prescritivo, no entanto, a Didática participa da trama das ações políticas, administrativas, econômicas e culturais contextualizadas, que incidem na práxis do ensino.

Reafirmar que o ensino, como prática social, constitui o seu campo de estudo significa também a interpretação desse objeto como fenômeno complexo que requer uma abordagem dialética e multirreferencial. O ensino como prática social vai tomando formas, transformando seus contextos e sendo transformado por eles; assim, ao continuar buscando a compreensão desse objeto em suas múltiplas formas e configurações, e fiel à sua perspectiva epistemológica, vai tomando feições cada vez mais perfiladas a esse processo de contínua transformação. Nesse diálogo, há compassos e descompassos, há ritmos afiados e ruídos dissonantes, há acertos e desacertos.

Grandes questões colocam-se hoje à didática:é possível ensinar tudo a todos? Ao ampliar a participação de todos os sujeitos, ao abrir espaços para a inclusão de todas as camadas sociais no processo de educação, a escola estremece e vacila muitas vezes: o que a didática tem que ver com isso? De quais professores precisamos hoje? Se ela tem a preocupação com o ensino, os concretizadores desse processo são os professores situados em contextos, e mais uma vez perguntamos: quais orientações e subsídios pode oferecer para a formação de professores? 
À medida que os processos de prática educativa se ampliam e se tornam mais complexos, os métodos de investigação desse fenômeno precisam ser reconfigurados. Assim perguntamos: o que a didática tem requisitado dos métodos de pesquisa em educação e, em contrapartida, como as novas inserções metodológicas têm permitido uma melhor compreensão da práxis educativa, ou seja, do espaço de concretização do ensino?

\section{DE EDUCAÇÃO, PEDAGOGIA E DIDÁTICA - BASES PARA ELUCIDAR APROXIMAÇÕES E ESPECIFICIDADES ENTRE DIDÁTICA, FORMAÇÃO DE PROFESSORES E CURRÍCULO}

Neste artigo, analisamos o percurso vivido pela didática nos últimos 20 anos, período no qual se observa a ausência de discussões relativas às relações entre educação, pedagogia e didática. Mais especificamente, no âmbito da ANPEd, analisamos as relações e diferenças entre o GT Didática e os posteriormente criados, o Formação de Professores (GT-08) e o Currículo (GT-12).

Esses temas ganharam relevo nos anos subsequentes à década de 1990, com a produção de pesquisas recentes ${ }^{1}$ sobre a identidade da pedagogia e das discussões geradas em torno das Diretrizes Curriculares Nacionais para o Curso de Graduação em Pedagogia, Licenciatura (Brasil, 2006), as quais acabaram por reduzir a formação de pedagogos em professores para os anos iniciais do ensino fundamental e por ampliar o esgarçamento da formação desses profissionais.

A discussão epistemológica ocorrida desde então está construindo um novo entendimento da didática, da pedagogia e das ciências da educação ${ }^{2}$ perante as necessidades da prática. Assim, tem-se afirmado que a pedagogia, ciência da educação, diferentemente das demais ciências da educação, toma a prática social da educação como ponto de partida e de chegada de suas investigações. Nesse sentido, é ciência da prática. A pedagogia como ciência da prática da educação é, ao mesmo tempo, constituída pelo fenômeno que a estuda e a constitui. Isso aponta para uma inversão epistemológica, pois até então a pedagogia fora considerada um campo aplicado de discursos alheios à educação enquanto prática social. A ressignificação epistemológica da pedagogia, que ainda está em curso, ocorre à medida que toma a prática dos educadores como referência e o modo como é produzido esse significado.

1 Após estudos sobre as questões epistemológicas e históricas da pedagogia no Brasil, afirmando a sua identidade e dos profissionais pedagogos (Bissoli da Silva, 2002; Franco; Pimenta; Libâneo, 2007; Libâneo, 1996, 2007; Libâneo; Pimenta, 1999; Mazzotti, 1996; Pimenta, 1996, 1997; Saviani, 2007,2010; Wachowicz, 2009), surgiram novas pesquisas teóricas e empíricas que contribuíram para explicitar a pedagogia como ciência da educação e a identidade profissional do pedagogo. São elas: Franco (2002, 2006), Franco, Pimenta e Libâneo (2007), Pinto (2002), Cruz (2008).

2 Um aprofundamento dessas relações pode ser verificado em Pimenta (1997). 
O objeto/problema da pedagogia é a educação como prática social, daí o caráter específico que a diferencia das demais: o de uma ciência da prática-que parte da prática e a ela se dirige. A problemática educativa e sua superação constituem o ponto de referência para a investigação. A educação, matéria de investigação da pedagogia, é um objeto inconcluso, histórico, que constitui o sujeito que a investiga e é por ele constituída. Por isso, não será captada na sua formalidade, mas, sim, na sua dialeticidade: no seu movimento, nas suas diferentes manifestações, como prática social, nas suas contradições, nos seus diferentes significados, nas suas diferentes direções, usos e finalidades. Será captada por diferentes mediações que revelam diferentes representações construídas sobre si.

Compete à pedagogia articular os diferentes aportes/discursos das ciências da educação, de significá-los no confronto com a prática da educação e diante dos problemas colocados pela prática social da educação. As ciências da educação e a pedagogia, por si, não modificam a educação, uma vez que as modificações ocorrem na ação. A elas compete alargar os conhecimentos dos educadores sobre sua ação de educar, nos contextos em que se situa (escola, sistemas de ensino e sociedade). Por isso, essas ciências serão significativas se tomarem intencionalmente a ação como objeto de estudo.

A didática, como área da pedagogia, estuda o fenômeno ensino. As recentes modificações nos sistemas escolares e, especialmente, na área de formação de professores configuram uma "explosão didática". Sua ressignificação aponta para um balanço do ensino como prática social, das pesquisas e das transformações que têm provocado na prática social de ensinar. Em que medida os resultados das pesquisas têm propiciado a construção de novos saberes e engendrado novas práticas, superadoras das situações das desigualdades sociais, culturais e humanas produzidas pelo ensino e pela escola?

Com essas indagações, aponta-se para a importância de um esforço coletivo dos pesquisadores e professores, em seus diferentes contextos institucionais locais, regionais, nacionais e internacionais, no intuito de efetivarem investigações e análises integradas do fenômeno educativo de ensinar, em equipes multidisciplinares, interdisciplinares e transdisciplinares. Não para delimitação de territórios, mas para significar a atividade científica que se volta para a educação como partícipe da construção de uma sociedade humana mais justa e igualitária.

Assim, considerando o ensino, situado historicamente em seus contextos (institucionais, culturais, geográficos, sociais, dos sujeitos que o realizam), desenvolvido por sujeitos professores que o têm como especificidade profissional, que atuam prioritariamente em escolas, cujo compromisso é concretizar a aprendizagem para o conjunto dos sujeitos crianças, jovens, adultos, ou seja, sujeitos professores comprometidos com a formação humana emancipatória, nas sociedades desiguais, ao GT Didática compete ser o espaço de apresentação e discussão de pesquisas que tenham como objeto essa prática.

Trazer pesquisas sobre e com professores faz sentido por esta ótica: que formação (que professor) se faz necessária para gerar o ensino e a aprendizagem nos contextos 
atuais? Também faz sentido pesquisas que tragam contribuições para melhor se compreender as determinações que o espaço escolar, sua organização e seu currículo têm sobre o trabalho docente de ensinar para gerar aprendizagens necessárias no contexto das desigualdades socioeconômicas e culturais no intuito de superá-las. Portanto, o GT Didática debruça-se sobre os campos da formação de professores e do currículo, tendo por centralidade o compromisso de ensinar dos professores, prioritariamente, nas escolas públicas, demanda necessária na sociedade atual.

Compreendendo, então, o ensino como prática social, pesquisas recentes na área apontam a importância dos estudos pautados nas metodologias que valorizam a atividade docente em contextos - como a pesquisa-ação crítico-colaborativa - e postulam a importância da construção de conhecimentos com os professores, elevando-os à condição de sujeitos e autores.

Alguns pesquisadores ampliam nossa reflexão sobre o ensino como prática social complexa e afirmam a importância de uma epistemologia que a tome nas situações históricas e sociais nas quais ocorre, valorizando a ação dos docentes na construção do saber didático.

Para Laneve (1993), a construção do saber didático dá-se não só pela pesquisa, mas também pela experiência dos professores, ou seja, daquilo que fazem e do que podem vir a fazer na escola. A prática dos professores é rica em possibilidades para a constituição da teoria. Contém saberes que advêm da ação direta, da intuição, do bom senso, da capacidade pessoal de julgamento, do poder de decisão.

Muitos fatos e pesquisas conduzem para a validação da didática, que nem sempre é reconhecida no seu aporte teórico, além da prática. Prática essa não menos significativa e essencial para a constituição do saber didático e para a competência profissional do docente. Mas como construir a teoria com base na prática? Entre outros fatores, Laneve aponta, como essencial, o registro sistemático das experiências, a fim de que se constitua a memória da escola. Memória que, analisada e refletida, contribuirá tanto com elaboração teórica quanto com o revigoramento e o engendramento de novas práticas. Assim, o estudo da tradição, o desenvolvimento da experiência e a discussão na área têm possibilitado em nossas pesquisas que os professores neles se ancorem para criar novos saberes didáticos.

Tomar a memória como base de novas experiências significa percebê-las como não generalizáveis, uma vez que são totalmente diferentes. É extremamente positivo retomá-las, porque evidenciam seus vínculos com os sujeitos e suas épocas; expressam que foram construídas por determinadas necessidades históricas. Por isso, não substituem o ensino e a pesquisa, ao contrário, exercitam o docente a refletir sobre a situação didática na qual está imerso.

Nesse sentido, entendemos que nas práticas docentes estão contidos elementos extremamente importantes, tais como a problematização, a intencionalidade para encontrar soluções, o alargamento de visão, a experimentação metodológica, o enfrentamento de situações de ensino complexas, as tentativas mais radicais, mais ricas e mais sugestivas de uma didática inovadora, que ainda não está configurada teoricamente. 
A importância da memória/estudo da experiência, segundo Laneve, constitui potencial para elevar a qualidade da prática escolar, assim como para elevar a qualidade da teoria. Esse entendimento implica uma reorientação da pesquisa na área: tomar o ensino escolar enquanto prática social como objeto de estudo da didática. $\mathrm{O}$ que não significa excluir uma reflexão mais geral sobre a educação, reflexão essa que tradicionalmente tem sido feita pela pedagogia. Ao contrário: não apenas é legítimo falar da pedagogia, mas, sobretudo, é a pedagogia que confere os significados, valora e baliza o sentido educativo da contribuição das outras ciências e da própria atividade docente, no que se refere ao alcance e sentido.

Diante da didática, a pedagogia, sem pretender exaurir os saberes com os quais se defronta, identifica e colhe de cada ciência indicações, problematizações e contribuições sobre o saber didático. As pesquisas recentes na área têm confirmado a construção do paradigma que Laneve (idem, p. 125) denomina de descolonização epistemológica da didática. Negando-a como mero campo aplicativo e técnico de uma ciência do conhecimento, o que a restringe ao como se aprende (dimensão técnica), e como transposição de indicações teóricas externas à compreensão das situações concretas de aprendizagem, configurando-se como consumo de conhecimento, o autor propõe ser a didática a aquisição original do conhecimento sobre o ensino.

Uma preocupação fundamental que Laneve revela é a de que o ensino como prática seja valorizado em teoria. Isto é, que se ultrapassem as formulações localizadas. Os professores, agindo racionalmente e resolvendo os muitos problemas nos seus contextos, não têm, automaticamente, consciência do modo como enfrentam e resolvem esses problemas. Adquirem essa consciência à medida que refletem sobre e pela sua prática, condição para que se construam novos saberes e para modificarem suas ações, ou seja, para teorizar.

Esse processo não é apenas individual. Há que se elevar esse nível, pela partilha de saberes, o que implica modificar a cultura das instituições formadoras (e das escolas, locais de trabalho), para possibilitar o desenvolvimento das habilidades de pensar, formar hábitos de pesquisa, de experimentação, de verificação, análise e problematização da própria prática. As novas pesquisas na área têm de recolher, articular e interpretar o conhecimento prático dos professores, não para criar uma literatura de exemplo, mas para estabelecer princípios, pressupostos, regras em campos de atuação.

É possível teorizar essas experiências e aplicá-las em outros contextos concretos? Não. Mas, assim, não se estaria reproduzindo a incomunicabilidade entre o pesquisador e o professor? Sem aprofundar esse problema, Laneve (idem, p. 132, tradução nossa) reconhece que, apesar dessa dificuldade, a tendência da pesquisa em didática pode ser sintetizada como se segue: "promover a passagem da mera idealização do discurso pedagógico à análise aprofundada das experiências de ensino, com vistas a descobrir a inteligência difusa, aquela sabedoria didática que os docentes expressam".

Contreras (1990), acentuando o ensino como objeto (não exclusivo da didática), define-o como uma prática humana e uma prática social. Ou seja, que 
compromete os envolvidos que se influenciam mutuamente. E responde a necessidades, funções e determinações que ultrapassam as intenções e previsões de quem a realiza. Nesse sentido, estudá-lo põe a necessidade de que se compreendam as estruturas sociais e o seu funcionamento e as relações que com estes a prática de ensinar estabelece.

$\mathrm{O}$ ato de ensinar escapa, pois, à prescrição dos especialistas. Na medida em que não se desenvolve como prática social autônoma, mas é parte integrante de dinâmicas que o extrapolam, escapa às decisões dos especialistas, exclusivamente. Diferentemente da prática médica tradicional (e inadequada), que em grande parte executa as prescrições científicas da medicina, o ensino não é prática orientada pela didática. Participa na trama das ações políticas, administrativas, econômicas e culturais contextualizadas (idem, p. 17). Consequentemente, para o autor, sua tarefa é, em primeiro lugar, tomar o ensino como prática social e compreender seu funcionamento como tal, sua função social, suas implicações estruturais. Em segundo lugar, realizar uma ação autorreflexiva de olhar a si mesma como componente do fenômeno que estuda.

Ou, conforme Popkewitz (1986, p. 215, tradução de Beatriz Affonso Neves), "o discurso da ciência não é apenas um instrumento para descobrir eventos, mas é parte do evento, ajudando a criar crenças sobre a natureza, causas, consequências e remédios das políticas educativas". Nesse sentido, evidencia a dimensão ética da didática, como ciência humana, que tem um caráter explicativo e projetivo, ao mesmo tempo. Por isso, provoca a geração de respostas novas. Não gera, por si, respostas. É na ação intencional, refletida, indagada, problematizada, ou seja, na práxis, na relação entre sujeitos, que se geram/transformam as práticas/resultados.

Esse entendimento leva a considerar o professor como figura fundamental. É ele que tem de compreender o funcionamento do real e articular sua visão crítica dessa realidade com suas pretensões educativas, a qual define e reformula, em virtude de contextos específicos. Isso significa definir o trabalho do professor como intelectual e não como técnico executor. Diferentemente dos paradigmas positivistas que operam uma tripla dicotomia - entre meios e fins, reduzindo a solução de problemas a uma dimensão técnica; entre a investigação e a prática, reduzindo esta última a uma aplicação de teorias; e entre saber e fazer, reduzindo a ação ao uso de procedimentos técnicos adequados -, a investigação que toma a prática como critério de verdade entende que teoria e prática são indissociáveis (Pimenta, 1996).

Assim, Contreras, referindo-se a Carr e Kemmis (1983), deduz que as diferenças entre uma e outra não são um problema de como aplicar a teoria à prática; mas são essas diferenças que constituem os autênticos problemas educativos, objeto da prática científica da área. Todos os problemas não revelam senão uma brecha, uma distância entre teoria e prática; uma brecha que significa um vazio entre a teoria e a realidade que se pretende compreender. No caso da didática, o que se põe em questão é a diferença que se abre entre a prática de ensino e a teoria com a qual se pratica, se experiencia, se compreende, se projeta. Ou seja, o problema consiste na discrepância entre a prática e a teoria que orienta a prática. E os desajustes resolvem- 
-se modificando-se a teoria, não a realidade. No caso dos problemas didáticos, os desajustes resolvem-se reorganizando-se tanto as teorias que orientam a prática quanto a própria ação de ensinar, e isso é seu caráter peculiar.

Analisando o avanço das investigações na área - que procuram superar a abordagem processo-produto -, Contreras (1990) reconhece as contribuições sobre o ensino que analisam as mediações: os processos cognitivos do aluno, os processos cognitivos do professor e as mediações sociais possibilitadas pelas investigações etnográficas e ecológicas da aula. No entanto, aponta para o fato de que essas abordagens, apesar de denotarem uma riqueza crescente de sua capacidade interpretativa, não têm se revelado como superadoras dos enfoques anteriores. Isso porque o paradigma processo-produto ainda é o dominante nos meios escolares e acadêmicos, não por seu vigor intelectual, mas porque se apresenta como "autoridade científica", capaz de resolver de modo simples e eficaz os problemas, ou seja, pauta-se em um conceito de eficácia, ideologicamente construído.

As novas abordagens, à exceção da ecológica, não têm sido suficientes para a formulação de novos conceitos de eficácia, valendo-se das práticas que analisam, ao se circunscreverem em exaustivas descrições da sala de aula. As abordagens ecológicas, ao contrário, mostram-se mais férteis, ao tomarem como foco de análise a sala de aula nos seus nexos com os múltiplos contextos curriculares, o que pode possibilitar a compreensão da estrutura e da dinâmica do real e a partir daí transformar-se.

\section{A ESCOLA COMO ESPAÇO PRIVILEGIADO DO ENSINO E DA DIDÁTICA}

As escolas estão fragilizadas e não conseguem ensinar tudo a todos; os educadores defrontam-se com a questão do o que ensinar, os professores, com o como ensinar, e toda sociedade ainda não tem resposta para a questão para que ensinar?

Em certa ocasião, por volta de setembro de 2010, deparamo-nos com uma pichação num muro de uma escola pública estadual paulista: "ensinar é impossível, aprender é inevitável!" Grande paradoxo que nos fez pensar: como a didática pode tornar possível o ensino? Um ensino que proceda à mediação reflexiva entre os valores e a cultura que a sociedade dissemina e os estudantes em formação? Pode ela sozinha dar conta dessa tarefa? É claro que não. No entanto, ela, como campo específico de conhecimento, tem uma responsabilidade social de acompanhar e refletir as mudanças que ocorrem no mundo e dar respostas para a ressignificação dos processos de ensino na perspectiva da aprendizagem do aluno.

Nunca é demais realçar que o seu papel se estrutura nas possibilidades de mediação entre o ensino, prioritariamente, na responsabilidade de professores, e a aprendizagem dos alunos e de todos aqueles que, nesse momento, são alunos, porque em situação de aprender. Entretanto, enfatizamos que didática é, acima de tudo, a construção de conhecimentos que possibilitem a mediação entre o que é preciso ensinar e o que é necessário aprender; entre o saber estruturado nas disciplinas e o saber ensinável mediante as circunstâncias e os momentos; entre as atuais formas de relação com o saber e as novas formas possíveis de reconstruí-las. 
Quando falamos de ensino, objeto de estudo da didática, preocupamo-nos em situar essa atividade na escola. Consideramos a escola o "ninho" fecundador das práticas docentes. Acreditamos que o ensino, dentro das salas de aula, é significado pelas condições de existência da escola, pelas condições de profissionalidade docente, pela articulação entre o projeto político-pedagógico e ações docentes.

Mas há que se pensar sobre a função social da escola, em especial da escola pública. Como nos alerta Nóvoa (2009, p. 13), a escola está tomando um rumo preocupante ao dualizar suas práticas e, assim, transformar-se em mais um canal de exclusão, distanciando-se de sua função emancipatória:

Um dos grandes perigos dos tempos atuais é uma escola a "duas velocidades": por um lado, uma escola concebida essencialmente como um centro de acolhimento social, para os pobres, com uma forte retórica da cidadania e da participação. Por outro lado, uma escola claramente centrada na aprendizagem e nas tecnologias, destinada a formar os filhos dos ricos.

Como a didática se coloca perante essa gritante contradição da sociedade que impõe às escolas públicas uma secundarização dos processos de ensino e formação, em prol do desvirtuamento de suas tarefas, para funcionar como espaço de guarda e acolhimento dos menos favorecidos?

Acreditamos que essa seja hoje, talvez, a sua função mais relevante, qual seja, a de buscar compreender e transformar a escola em local de ensino e formação. Como já realçado (Pimenta et al., 2008) em nosso projeto coletivo de pesquisa: reinventar a escola para os tempos de hoje não se trata de voltar à escola apenas preocupada com conteúdos, mas, sim, uma escola que amplie e reconfigure a função social do ensino. Como nos lembra Libâneo (1998, p. 19):

[...] penso que escola para a democracia e para a emancipação humana é aquela que, antes de tudo, através dos conhecimentos teóricos e práticos, propicia as condições do desenvolvimento cognitivo, afetivo e moral dos alunos. $\mathrm{O}$ melhor ensino é o que impulsiona o desenvolvimento mental. E que faça isso para todos os que disponham das competências físicas e intelectuais requeridas para isso. Aprender, então, consiste no desenvolvimento de capacidades e habilidades de pensamento necessárias para assimilar e utilizar com êxito os conhecimentos. [...] Sendo assim, a tarefa das escolas fica muito clara, que é assegurar as condições para que a aprendizagem escolar se torne mais eficaz, mais sólida, mais consolidada, enquanto ferramenta para as pessoas lidarem com a vida.

Essa tarefa não se faz isoladamente, nem se faz intuitivamente. As condições de profissionalização são fundamentais e a didática poderá conferir sentidos à prática docente quando ampliar seu olhar para o contexto coletivo dessa prática que é a escola.

Afirmando que o ensino e a aprendizagem, tomados na prática social, constituem o objeto da didática, Contreras (1990) estabelece entre ambos uma relação 
de dependência ontológica. À didática cabe "desnaturalizar” o ensino. Isso significa, em primeiro lugar, considerar o ensino e a aprendizagem que ocorrem não só na sala de aula, mas nos contextos sociais mais amplos. A compreensão do fenômeno ensino-aprendizagem não se esgota no acontecimento aula. Em segundo lugar, é necessário que se estabeleçam seus vínculos com as decisões curriculares, com os modos como a escola se organiza, sua estrutura administrativa, a legislação, a organização espaço-tempo, as condições físicas e materiais que condicionam as práticas escolares. É preciso analisar os processos que operam na formação do conhecimento dos alunos, em situação concreta de ensino, e suas relações com o currículo explícito e/ou oculto, do qual procede o conhecimento que se ensina na escola.

Essa complexidade, do ensino em situação, realça a responsabilidade social dos professores com o ensino. Dessa maneira, a didática não pode deixar de levar em conta a preocupação com as condições de formação dos docentes e com as condições de trabalho desses profissionais, especialmente no âmbito da escola.

Assim, reafirmamos que o seu foco é a escola, como espaço privilegiado do ensino. Não se pode apenas focar o olhar na sala de aula, quando estudos de Sacristán $(1999,2005,2006)$ e de Sacristán e Pérez-Gómez (1998) reafirmam que o ensino cria sentidos quando inserido num projeto coletivo; um projeto político-pedagógico tecido e permeado pelas condições de possibilidade do exercício profissional.

Desse modo, tendo esse foco direcionador do olhar, a didática interessa-se pelos temas básicos que a acompanharam no decorrer dos séculos: organização dos processos de ensino; planejamento de ensino; concretização de planos de trabalho docente; ensino em situação; processos de acompanhamento e avaliação; análise dos contextos; formação de docentes, entre outros.

Essa complexidade de temáticas não é uma dispersão, mas assuntos e situações que estão atrelados à condição de ensino. Outras questões ainda rebatem nesses temas, tais como: a questão do currículo; do saber ensinável (transposição didática); das práticas multiculturais; os processos de inclusão social/cultural; os novos recursos de apoio ao ensino, digitais ou não; os projetos prévios que são impostos à escola; as formas de tutela à prática docente; as organizações espaçotemporais da escola, como, por exemplo, a escola em ciclos, entre outras.

\section{A DIDÁTICA COMO RESSONÂNCIA E REVERBERAÇÃO}

Tendo como foco essa amplitude de temáticas, é de se esperar que as contradições sejam a tônica desse campo conceitual, configurando o constante desafio que os educadores têm enfrentado para ressignificar o papel do ensino, da aprendizagem, da escola e dos professores perante as demandas do mundo contemporâneo.

Qual a responsabilidade da didática diante dessas contradições?

Se é considerada como um campo de estudos e pesquisas voltado para a tarefa de fundamentar o processo ensino-aprendizagem como uma prática social de incorporação e de emancipação política, isso impõe a essa área de conhecimento o papel de refletir as demandas dessa prática perante as novas expectativas sociais. 
Talvez, a sua principal tarefa para fundamentar a produtiva concretização do processo de ensinar-aprender será a de, ao tomar o ensino como prática social, buscar compreendê-lo em todas as suas determinações, olhar-se assim inserida nessa prática e ir dialogando com esse processo na busca de articulações cada vez mais produtivas entre as demandas do momento e as possibilidades que a prática evidencia.

No processo de ação-reflexão, reflexão-ação, açãorreflexãoação, a didática vai se constituindo, adquirindo novas configurações, propondo novas perspectivas.

No entanto, dadas as condições difíceis em que se coloca a escola hoje, as condições de pauperização dos docentes, a falta de um pacto social de valorização da escola e, em especial, da escola pública, a didática tem sido desafiada: como encontrar espaços de significação diante de tantas condições desfavoráveis?

Estamos realçando que ela estará sempre impregnada das contradições impostas pelo momento histórico atual. Errará se não tomar para si as contradições e se, a partir destas, não buscar produzir conhecimentos e práticas.

Conforme já mencionamos no início deste artigo, pode-se dizer que a didática, em sua origem, com Comênio, surge como instrumento político para romper com a hegemonia da educação católica medieval. Portanto, já em seu início, ela surge do e no enfrentamento das contradições políticas, éticas e sociais.

O mesmo ocorre em diferentes momentos históricos, e um dos mais marcantes foi no início da década de 1980, quando a didática foi posta em questão (Candau, 1983). Novamente, observamos a didática reverberando os movimentos sociais dos trabalhadores no período pós-Ditadura e no bojo de movimentos sociais de reorganização da sociedade civil brasileira.

Constituíram-se, naqueles anos, movimentos sociais como sindicatos, organizações em prol da saúde e educação, lutas por moradia, organizações para assentamento dos sem-terra. Organizaram-se as Conferências Brasileiras de Educação (CBEs), os encontros nacionais de pesquisadores em educação, como o Encontro Nacional de Didática e Prática de Ensino (ENDIPE), a criação da ANPEd, entre outros.

Naquela época, houve fortes movimentos que buscavam a transformação das escolas, dos currículos, das práticas pedagógicas. Assim, fortaleceu-se a organização dos professores em sindicatos, acentuaram-se os movimentos reivindicatórios dos docentes, surgiram as greves, ampliaram-se os cursos de formação de professores e surgiram as lutas pela profissionalização dos docentes. A didática, como um campo de conhecimento em permanente construção, assumiu as questões pedagógicas como base para a sua produção, inseriu a questão política como determinante das questões pedagógicas e se opôs à didática instrumental, fincando as bases de uma didática fundamental. Mais uma vez, percebe-se esse campo do conhecimento ser tocado, sensivelmente, pelas questões mais amplas que estavam sendo apontadas pelos movimentos sociais, pelo mundo do trabalho e pela ação dos sujeitos sócio-históricos e, novamente, reverbera e reinterpreta os desafios do mundo atual.

Justifica-se, assim, a dispersão temática que viemos presenciando ao observar a trajetória e as pesquisas na área. Por certo, uma dispersão necessária para tentar 
compreender o seu foco, seu objeto de estudo, sem descaracterizá-lo pela simplificação e fragmentação. Para compreendermos o recente processo vivido pela didática, neste texto tomamos por base a evolução das temáticas que foram e estão sendo estudadas nas reuniões anuais da ANPEd. Há que se lembrar que essas reuniões anuais configuram-se como "vitrines" do que se passa no campo da didática, no que se refere a pesquisas, tendências, inovações na área. É esse caráter de exposição e socialização dos conhecimentos produzidos que confere sentido à reconstituição do panorama da área, valendo-se do que lá ocorre.

\section{DA DISPERSÃO TEMÁTICA À RECONFIGURAÇÃO DO CAMPO}

Em balanço analítico realizado por Pimenta et al. (2000), a respeito da produção de conhecimento no campo da didática, apresentada para discussão no GT Didática da ANPEd, encontramos algumas características que ajudam a compreender a reconfiguração de seu campo.

Um primeiro aspecto refere-se às temáticas abordadas nas pesquisas, em que se destacam preocupações com a epistemologia e as bases teóricas da didática; suas articulações com a docência e a pesquisa; as teorias educacionais e os contextos escolares; as metodologias, as relações comunicacionais e as técnicas de ensino; as práticas pedagógicas de ensino em novos contextos de políticas educacionais; a avaliação; a formação inicial e contínua de professores; o ensino e a aprendizagem, bem como balanços de pesquisas em campos específicos de ensino.

Essa ampla abordagem temática pode ser compreendida pelo paradigma da multirreferencialidade como sendo expressão da complexidade da área, cujo foco é o ensino enquanto prática social, que, necessariamente, leva em consideração os sujeitos envolvidos, bem como os contextos em que se desenvolve. Outra evidência é a forte presença da análise das práticas pedagógicas, que toma as situações de sala de aula e dos contextos escolares como objeto de investigação, estabelecendo nexos com as teorias didáticas e pedagógicas.

Mesmo em pesquisas que tratam a didática e seus temas clássicos, como avaliação, metodologias, relação comunicacional e técnicas, ensino e aprendizagem, é possível encontrar indícios inovadores na abordagem, que toma como objeto de análise as situações concretas nas quais as práticas ocorrem, buscando compreender o ensino nas relações professor-aluno-conteúdos e em seus contextos e pelas inúmeras referências teóricas e metodológicas.

Também é possível perceber o aparecimento de temáticas novas, como a que trata a didática e suas articulações com a temática da docência na universidade, o que implode a compreensão de que seu campo se reduz ao ensino e à aprendizagem de crianças e adolescentes. Ao entendê-la também como fundante da educação de adultos em processos mais avançados de aprendizagem, as pesquisas buscam disponibilizar conhecimentos pedagógicos para que os professores realizem uma autêntica análise crítica da cultura pedagógica presente no ensino superior e busquem produzir respostas concretas às dificuldades encontradas no trabalho de ensinar. 
Outro aspecto relevante refere-se às categorias de análise, que se desdobram em quatro conjuntos: a) o processo ensino-aprendizagem; b) as concepções de professor e de formação docente; c) o trabalho docente nas escolas; d) as finalidades do processo ensino-aprendizagem. $\mathrm{O}$ volume de categorias contidas nesses eixos evidencia a apropriação dos procedimentos de investigação, bem como o desenvolvimento e a consolidação da pesquisa de natureza teórica e de campo na área.

No que toca às abordagens metodológicas, destacam-se as de natureza teórica e as que tomam a prática pedagógica como objeto de análise, centrando-se na compreensão dos fenômenos educativos numa perspectiva compreensiva, que busca construir conhecimento na inter-relação com as explicações teórica e historicamente sustentadas. As atuais abordagens da epistemologia da prática, compreendendo o ensino como fenômeno complexo e o espaço escolar numa perspectiva ecológica, apontam para uma possível superação de uma perspectiva individualista por uma perspectiva pública (de compromisso social) das práticas escolares.

Quanto às conclusões elou resultados, as pesquisas evidenciam coerência entre as compreensões finais, os propósitos e as discussões presentes no campo. De modo geral, apontam para transformações epistemológicas, teórico-metodológicas e das práticas cotidianas, abrindo espaços para a incorporação de novos conceitos e enfoques.

A respeito das bases bibliográficas, a leitura feita identificou tendências como teorias didáticas; didática crítica; avaliação; formação e profissionalização de professores (reflexivos); relação sociedade e educação (com destaque para trabalho e educaşão, exclusão social, cultura escolar); currículo; novas tecnologias; novas linguagens (narrativas, imaginário); pesquisa-ação; modernidade e pós-modernidade; teorias da complexidade; projeto pedagógico; planejamento; interdisciplinaridade. Esse amplo quadro teórico indica também o alargamento das visões multirreferenciais do fenômeno ensino-aprendizagem.

Em estudos mais recentes, temos o trabalho de Fernandes e Leite (2007), em que as autoras realizaram um levantamento em relação à produção do GT Didática nos 30 anos de existência da ANPEd e reafirmaram, com base na análise de 317 trabalhos, as temáticas mais presentes nas investigações ali realizadas: teorização sobre a didática: 97 trabalhos; formação docente: 42 trabalhos; metodologias/práticas: 41 trabalhos; ensino e aprendizagem de (conteúdos específicos): 36 trabalhos; avaliação: 29 trabalhos; saberes docentes: 25 trabalhos; o professor: 14 trabalhos; projeto pedagógico: 8 trabalhos; material didático: 7 trabalhos; a escola: 5 trabalhos; pesquisa e ensino: 5 trabalhos; sobre a prática de ensino: 4 trabalhos; a aula: 3 trabalhos; e aluno: 1 trabalho.

As autoras realçam ainda a diversidade metodológica, incluindo trabalhos etnográficos, de pesquisa-ação, estudos exploratórios, estudo de caso, pesquisa participante, entre outros, mostrando a fecundidade das diferentes abordagens que têm sido utilizadas nos estudos da área.

Em outro estudo, Urt e Morettini (2004), interessadas em estudar a apropriação pela área de questões e conceitos de psicologia, fizeram um levantamento dos 
trabalhos apresentados no GT Didática nos anos de 1998-2004. Centralizaram as temáticas em seis eixos prioritários, dos 49 trabalhos analisados do GT Didática, e ficaram assim distribuídas: aprendizagem escolar: 13 trabalhos; didática: 9 trabalhos; contexto escolar: 8 trabalhos; identidade do professor: 7 trabalhos; novas tendências: 7 trabalhos; e práticas inovadoras: 5 trabalhos.

As temáticas revelam, segundo as autoras, as mais diversas preocupações e demonstram ter recebido influência das propostas do movimento da década anterior, sinalizando duas tendências: uma que procura pontuar a didática como campo teórico ou tenta estudá-la como disciplina nos cursos de formação para professores, e outra que expressa cuidados com o processo de ensino e de aprendizagem, em suas múltiplas implicações. Realçam, ainda, que começa a aparecer, nos últimos anos, uma terceira tendência, que é a aprendizagem realizada fora do espaço escolar ou a distância.

No período estudado, os assuntos variam, sobressaindo-se trabalhos que procuram especificar a didática como área de estudo, o que revela a busca de seus estudiosos pelas questões ligadas à conceituação desse campo. Após 1998, como novidade, aparecem os trabalhos que estudam a interdisciplinaridade e a cultura escolar, que se apresenta como um novo universo a ser investigado. Os pesquisadores voltam-se para o cotidiano da escola, investigando a realidade, observando o que está acontecendo e sendo produzido lá dentro e procurando encontrar explicações. Eles não se mostram satisfeitos apenas com a visão dos professores, precisam ir a campo, fazer parte da equipe de profissionais e melhorar a qualidade da "escuta".

O pesquisador, nesse sentido, é alguém que, com sua bagagem, pode ajudar o professor a ter um melhor enfoque da realidade. Realçam as autoras que o foco das pesquisas vai saindo do aluno e vai passando para a escola. No final do período pesquisado, surgem trabalhos que envolvem a educação continuada e a distância, bem como a educação em instituições não escolares.

Como se pode perceber, esses estudos abrangem quase duas décadas de pesquisas. A tendência investigativa recai de alguma forma em quatro polos: nas práticas docentes, consideradas como um espaço de formação (aqui entrariam as temáticas focadas no professor/saberes/metodologias/inovações); no contexto dessas práticas, focando a escola e seus condicionantes (aqui entrariam as questões de profissão/ profissionalização/condições de exercício profissional/identidade), e, ainda, uma terceira perspectiva seriam os estudos que buscam fazer as mediações entre ensino e aprendizagem (desde o planejamento de aula até as condições institucionais e de gestão).

Para além desses três recortes, o GT Didática abriga ainda os estudos de cunho epistemológico sobre a própria didática e demais ciências que tomam o ensino como objeto de estudo.

Apesar da diversidade possível das temáticas, esses polos podem funcionar como balizadores da abrangência temática. No entanto, há que se realçar que as temáticas, para se constituírem como objeto de estudo do GT Didática, precisam estabelecer mediações com a perspectiva do campo da didática e tentar responder 
às questões fundamentais: como o estudo contribui para a melhor compreensão dos processos de ensino-aprendizagem? Como a investigação contribui para a operacionalização do ensino em seu espaço primordial, qual seja, a escola? De que forma a pesquisa amplia as possibilidades da atuação da didática como prática pedagógica da/na escola?

\section{A QUESTÃO METODOLÓGICA NAS PESQUISAS EM DIDÁTICA}

Podemos afirmar que à medida que a área foi refinando e aprofundando seu foco de investigação, por conta das possibilidades de utilização de instrumentos investigativos cada vez mais articulados à característica do seu objeto, este foi se mostrando cada vez mais complexo e multiforme. Assim, podemos concluir que para o estudo de um objeto complexo não cabem metodologias que não captem tal singularidade.

Conforme Franco (2006), a metodologia de pesquisa em educação deve ser concebida como um processo que organiza cientificamente todo movimento reflexivo, do sujeito ao empírico, e deste ao concreto, até a organização de novos conhecimentos que permitam uma nova leitura/compreensão/interpretação do empírico inicial. Essa concepção de metodologia é denominada de reflexiva, que reafirma, de acordo com Pinto (1969), as necessárias articulações entre ciência e existência, uma vez que o pensamento teórico não existe desligado do plano objetivo, da prática; ou que seja sem utilidade para esta, assim como não há trabalho, nem ação prática sobre o mundo, que não dê como resultado uma representação teórica e não determine o aparecimento de novas ideias ou a descoberta de relações inéditas entre estas.

A metodologia, vista como organizadora e desafiadora da reflexão, passa assim a funcionar como a cientificizadora das relações que se estabelecem entre o ato de pesquisar e as novas compreensões que se vão erigindo do diálogo do pesquisador com o mundo.

A metodologia da pesquisa, dentro dessa abordagem reflexiva, caracteriza-se fundamentalmente por ser a postura crítica que organiza a dialética do processo investigativo; que orienta os recortes e as escolhas feitas pelo pesquisador; que direciona o foco e ilumina o cenário da realidade a ser estudada; que dá sentido e redireciona as abordagens do pesquisador; que organiza, enfim, a síntese das intencionalidades da pesquisa.

Assim, afirmamos que a metodologia da pesquisa não é um rol de procedimentos a seguir, nem um manual de ações do pesquisador, nem mesmo um caminho engessador da necessária criatividade do pesquisador. A metodologia organiza-se em torno de um quadro de referências, quadro este decorrente de posturas, crenças, valores, que se configuram por formas de concepções de mundo, de vida, de conhecimento.

A metodologia é também a organização do pensamento reflexivo-investigativo durante todo processo da pesquisa. A metodologia deve institucionalizar os questionamentos em todas as fases do pesquisar. Instalar o questionamento e refleti-lo sob 
a luz do quadro de referências imanentes à metodologia escolhida: a metodologia deve ser o exercício contínuo da dúvida metódica.

Assim, espera-se que os trabalhos do GT Didática sejam tecidos metodologicamente de forma que haja sempre o diálogo do objeto com o contexto significador da área, ou seja, vincular-se e dialogar com a perspectiva do ensino, de forma contextualizada e crítica. Cada um de seus possíveis focos de estudo dará sentido à área à medida que for trabalhado pela e por meio da intencionalidade da área.

Gatti (2002, p. 52) é bem incisiva nesse ponto, ao comentar que ainda carecemos de massa crítica de bons pesquisadores: "Há que se debruçar sobre as questões de base, há que se manter a capacidade de questionamento viva e atuante, há que se ter solidez teórica e dúvida metódica, há que se temer dogmas e verdades fáceis e antecipadas".

\section{CONSIDERAÇÕES FINAIS}

Esperamos que as reflexões tecidas neste texto colaborem com o GT Didática e com os pesquisadores da área, no sentido de afirmar a necessidade de o conhecimento produzido e em produção não perder de vista o ensino como fenômeno complexo, bistórica e institucionalmente situado, objeto especifico da didática.

Considerando que o ensino é realizado em instituições específicas, preferencialmente nas escolares, e realiza-se por e entre sujeitos, professores e alunos, em contínuos processos de mediação entre diferentes contextos e circunstâncias, parece-nos oportuno apontar que os estudos e pesquisas que se debruçam sobre as questões do ensino escolar devem ser pesquisados, compreendidos, analisados na perspectiva da totalidade. Assim, espera-se que a pesquisa na área, ao focar as mediações entre o ensinar e aprender, considere que essas mediações são condicionadas e atravessadas por múltiplas determinações, tais como: as configurações dos sistemas escolares e escolas, as políticas e dinâmicas dos processos curriculares, as práticas pedagógicas de gestão escolar, os impactos das políticas públicas nas práticas docentes.

Reafirmamos que as pesquisas em didática não podem isolar o fenômeno educativo de suas circunstâncias, nem de sua temporalidade; é preciso realçar que sua especificidade revela seu compromisso: partir do ensino como prática social e dar respostas socialmente significativas para transformar as condições de precariedade dos resultados de aprendizagem observados na atual escola brasileira. Esses pífios resultados afastam a escola de sua função social básica de democratização do conhecimento e de partícipe nos processos de transformação das desigualdades sociais.

Situar suas pesquisas no centro dessa contradição nos parece ser o desafio posto para o GT Didática. Esse nos parece o critério para a seleção dos trabalhos a serem apresentados no seu espaço privilegiado, no âmbito da ANPEd, nossa associação maior de difusão e discussão pública dos resultados sociais do trabalho dos pesquisadores (parafraseando Álvaro Vieira Pinto, na obra Ciência e existência, 1969).

É nesse quadro de intencionalidade que os pesquisadores buscam reafirmar os compromissos e a especificidade da área de didática, num diálogo necessário e fertilizador com os demais GTs que focam suas investigações sobre os processos 
de ensinar-aprender, com base em aportes teóricos de suas áreas. Como exemplo, o GT Formação de Professores; GT Psicologia; GT Currículo; GT Políticas Públicas; GT História da Educação, entre outros.

As pesquisas na área serão nutridas das contribuições desses campos à medida que oferecerem perspectivas que ampliem e fertilizem as análises e interpretações dos problemas que emergem de seu campo específico, que é o ensino e a aprendizagem. Portanto, não se trata de diluição ou dispersão de seu campo, como às vezes se afirma, mas, ao contrário, de se considerar seu objeto - o ensino e a aprendizagem - como um fenômeno complexo, que só pode ser compreendido pelas categorias de totalidade e contradição.

\section{REFERÊNCIAS}

Bissolli da Silva, Carmem Silvia. Curso de pedagogia no Brasil: uma questão em aberto. In: Pimenta, Selma Garrido (Org.). Pedagogia e pedagogos: caminhos e perspectivas. São Paulo: Cortez, 2002. p. 129-152.

Brasil. Ministério da Educação. Conselho Nacional de Educação. Resolução n. 1/2006, de 15 de maio de 2006. Institui Diretrizes Curriculares Nacionais para o Curso de Graduação em Pedagogia, Licenciatura. Diário Oficial da União, Brasília, DF, 16 maio 2006. Seção 1, p. 11.

Candau, Vera Maria Ferrão (Org.). A didática em questão. Rio de Janeiro: Vozes, 1983. (Org.). Didática - questões contemporâneas. Rio de Janeiro: Editora Forma \& Ação, 2009.

Carr, Wilfred; Kemmis, Stephen. Becoming critial: knowing through action research. Victoria: Deakin University, 1983.

Comênio. Didática magna. São Paulo: Martins Fontes, 1997.

Contreras, José. Enseñanza, curriculum y profesorado - introducción crítica a la didáctica. Madri: Akal, 1990.

$\mathrm{C}_{\mathrm{RUZ}}$, Giseli Barreto da. O curso de pedagogia no Brasil na visão de pedagogos primordiais. 2008. Tese (Doutorado) - Pontifícia Universidade Católica do Rio de Janeiro, Rio de Janeiro, 2008.

Fernandes, Cleoni Maria Barboza; Leite, Yoshie Ussami Ferrari. 30 anos de estudos didáticos: recorrências, mudanças, riquezas e problemas. Caxambu: Documento do Grupo de Trabalho Didática, ANPEd, 2007.

Franco, Maria Amélia Santoro. Para um currículo de formação de pedagogos. In: Pimenta, Selma Garrido (Org.). Pedagogia e pedagogos: caminhos e perspectivas. São Paulo: Cortez, 2002. p. 99-127.

. A pedagogia como ciência da educação. 2. ed. São Paulo: Cortez , 2006.

Didática e pedagogia. Da teoria de ensino à teoria da formação. In: Pimenta, Selma Garrido; Franco, Maria Amélia Santoro (Orgs.). Didática - embates contemporâneos. São Paulo: Edições Loyola, 2010. p. 75-99. 
.; Pimenta, Selma Garrido; LibÂneo, José Carlos. Elementos para a formulação de diretrizes curriculares nacionais para cursos de pedagogia. Cadernos de Pesquisa, São Paulo, Fundação Carlos Chagas, v. 37, n. 130, p. 63-98, jan./abr. 2007.

Fusari, José Cerchi; Franco, Maria Amélia Santoro. Apresentação. In: Pimenta, Selma Garrido; Franco, Maria Amélia Santoro (Orgs.). Didática - embates contemporâneos. São Paulo: Edições Loyola, 2010. p. 7-15.

Gatti, Bernardete Angelina. A construção da pesquisa em educação no Brasil. Brasília: Editora Plano, 2002.

Laneve, Cosimo. Per una teoria della didattica. Brescia: Ed. La Scuola, 1993.

LibÂneo, José Carlos. Que destino os educadores darão à pedagogia? In: Pimenta, Selma Garrido (Org.). Pedagogia, ciência da educação? São Paulo: Cortez, 1996. p. 107-134.

. Pedagogia e pedagogos, para quê? São Paulo: Cortez, 1998.

. Ainda as perguntas: o que é pedagogia, quem é o pedagogo, o que deve ser o curso de pedagogia. In: Pimenta, Selma Garrido (Org.). Pedagogia epedagogos: caminhos e perspectivas. São Paulo: Cortez, 2002. p. 59-98. (mimeo.).

Que são "questôes" no campo investigativo da pedagogia? Goiânia: UCG, 2007.

.; Pimenta, Selma Garrido. Formação dos profissionais da educação: visão crítica e perspectivas de mudança. Educą̧ão E Sociedade, Campinas, CEDES, v. 20, n. 68, p. 278-298, dez. 1999.

Mazzotti, Tarso Bonilha. Estatuto de cientificidade da pedagogia. In: Pimenta, Selma Garrido (Org.). Pedagogia, ciência da educação? São Paulo: Cortez, 1996. p. 13-38.

NóvoA, António. Professores: imagens do futuro presente. Lisboa: EDUCA. 2009.

Pimenta, Selma Garrido (Org.). Pedagogia, ciência da educação? São Paulo: Cortez, 1996.

. Para uma ressignificação da didática: ciências da educação, pedagogia e didática (uma revisão conceitual e uma síntese provisória). In: _. Didática e formação de professores: percursos e perspectiva no Brasil e em Portugal. São Paulo: Cortez, 1997. p. 19-77.

(Org.). Pedagogia e pedagogos: caminhos e perspectivas. São Paulo: Cortez, 2002a. p. 129-152.

. De professores, pesquisa e didática. Campinas: Papirus, 2002b.

.Epistemologia da prática ressignificando a didática. In: ; Franco, Maria Amélia Santoro (Orgs.). Didática - embates contemporâneos. São Paulo: Edições Loyola, 2010. p. 15-41.

.; Lisita, Verbena Moreira Soares de Sousa. Pesquisas sobre professores e sua formação: uma análise das pesquisas desenvolvidas no programa de pós-graduação em educação da FEUSP de 1990 a 1998. Educar em Revista, Curitiba, Universidade Federal do Paraná, n. 24, p. 87-112, jul./dez. 2004. 
. et al. A pesquisa em didática (1996-1999). In: CAndau, Vera Maria Ferrão (Org.). Didática, currículo e saberes escolares. Rio de Janeiro: DP\&A, 2000. p. 78-106. . et al. Projeto de pesquisa na área de formação de professores e suas contribuições para a reinvenção do trabalho docente, do espaço escolar e das politicas educacionais. GEPEFE (Grupo de Estudos e Pesquisas sobre Formação do Educador). São Paulo: USP, 2008. Pinto, Álvaro Vieira. Ciência e existência: problemas filosóficos da pesquisa científica. Rio de Janeiro: Paz e Terra, 1969.

Pinto, Umberto de Andrade. O pedagogo escolar: avançando no debate a partir da experiência desenvolvida nos cursos de complementação pedagógica. In: Pimenta, Selma Garrido (Org.). Pedagogia e pedagogos: caminhos e perspectivas. São Paulo: Cortez, 2002. p. 99-128.

Pop кEwitz, Thomas. The social contexts of schooling: change and educacional research. New York: Taylor, 1986.

Rios, Terezinha Azeredo. Compreender e ensinar. São Paulo: Cortez, 2001.

Sacristán, Gimeno. Poderes instáveis em educação. Porto Alegre: Artmed, 1999. . La educación que aún es posible. Madrid: Ed. Morata, 2005.

. La reforma necesaria: entre la política educativa y la práctica educativa.Madrid: Morata y Gobierno de Cantabria, 2006.

.; Pérez-Gómez, Angel Ignacio. Aprender e transformar o ensino. Porto Alegre: Artmed, 1998.

Saviani, Dermeval. Pedagogia: o espaço da educação na universidade. Cadernos de Pesquisa, São Paulo, Fundação Carlos Chagas, v. 37, n. 130, p. 99-134, abr. 2007.

. Interlocuçôes pedagógicas: conversa com Paulo Freire e Adriano Nogueira e 30 entrevistas sobre educação. Campinas: Autores Associados, 2010.

URT, Sônia da Cunha; Morettini, Marly Teixeira. Análise da produção da didática: temáticas e formas de apropriação das ideias psicológicas. In: ENCONTRo NACIONAL de Didática e Prática de Ensino, 12., 2004, Curitiba. Anais... Curitiba, PUC-PR, v. 1, p. 3.324-3.336, agosto 2004.

Wachowicz, Lílian Anna. Pedagogia mediadora. Rio de Janeiro: Vozes, 2009.

\section{SOBRE OS AUTORES}

Selma Garrido Pimenta é doutora em educação pela Pontifícia Universidade Católica de São Paulo (PUC-SP). Professora titular da Universidade de São Paulo (USP).

E-mail:sgpiment@usp.br

José Cerchi Fusari é doutor em educação pela Universidade de São Paulo (USP). Professor da mesma instituição.

E-mail: jcfusari@usp.br 
Maria Isabel de Almeida é doutora em didática pela Universidade de São Paulo (USP). Professora da mesma instituição.

E-mail:mialmei@usp.br

Maria Amélia do Rosário Santoro Franco é doutora em educação pela Universidade de São Paulo (USP). Professora da Universidade Católica de Santos (UNISANTOS).

E-mail: ameliasantoro@uol.com.br

Recebido em fevereiro de 2011 Aprovado em junho de 2012 


\section{SELMA GARRIDO PIMENTA, JOSÉ CERCHI FUSARI, MARIA ISABEL DE ALMEIDA E MARIA AMÉLIA DO ROSÁRIO SANTORO FRANCO}

\section{A construção da didática no GT Didática - análise de seus referenciais}

Ao considerarmos as condições difíceis em que se coloca a escola hoje, a didática tem sido desafiada a encontrar novos espaços de significação. Como agir/pensar didaticamente quando não há condições mínimas para a organização de um espaço/ tempo educacional que valorize o ensinar e o aprender? Neste artigo, propusemo-nos a analisar a produção teórica e as pesquisas produzidas nos últimos 20 anos (1988-2008) no Grupo de Trabalho Didática (GT-04) da Associação Nacional de Pós-Graduação e Pesquisa em Educação (ANPEd). Partimos do pressuposto de que, quer como campo teórico, quer como prática social, ela funciona como caixa de ressonância e de reverberação dos desafios que o contexto socioeconômico e político propõe à tarefa educativa. Observamos no conjunto dos trabalhos analisados uma certa dispersão epistemológica e de paradigmas nas pesquisas da área. As pesquisas realizadas reafirmam quatro focos de análise: as práticas docentes; os contextos da prática; as mediações entre ensino e aprendizagem e as pesquisas de cunho epistemológico.

Palavras-chave: especificidade didática; ensino; aprendizagem; epistemologia. The construction of didactics in the didactics' work group analysis of its references

In the face of the difficult conditions under which schools work today, Didactics has been challenged to find new spaces of meaning. How can one act/ think didactically 
when there are no minimal conditions for the organization of an educational spacel time which values teaching and learning? In this article we propose to analyze the theoretical production and research conducted over the past twenty years by the Didactics $W G$ of the National Association of Graduate Studies and Research in Education (ANPEd). We assume that both as a theoretical field and as a social practice, it works as a sounding and reverberation box of the challenges that the socioeconomic and political context poses to the educational task. In all the studies analyzed we observed some epistemological and paradigm dispersion. The studies carried out reiterate four foci of analysis: teaching practices; contexts of practice; mediations between teaching and learning; and epistemological research.

Keywords: didactic specificity; teaching; learning; epistemology.

\section{La construcción de la didáctica en el GT de didáctica - análisis de sus referenciales}

Al considerar las difíciles condiciones en la que se encuentra la escuela hoy, la Didáctica ha sido desafiada a encontrar nuevos espacios de significación. ¿Cómo actuar/ pensar didácticamente cuando no hay condiciones minimas para la organización de un espacio/tiempo educacional que valore la enseñanza y el aprendizaje? En este artículo, nos propusimos analizar la producción teórica y las investigaciones producidas en los últimos veinte años en el Grupo de Trabajo Didáctica de la Asociación Nacional de Posgrado y Pesquisa en Educación (ANPEd). Partimos del presupuesto que, sea como campo teórico, sea como práctica social, funciona como caja de resonancia y de reverberación de los desafios que el contexto socio-económico-político propone a la tarea educativa. Observamos en el conjunto de los trabajos analizados, una cierta dispersión epistemológica y de paradigmas en las investigaciones del área. Las investigaciones realizadas reafirman cuatro focos de análisis: las prácticas docentes; los contextos de las prácticas; las mediaciones entre enseñanza y aprendizaje y las investigaciones con objetivo epistemológico.

Palabras clave: especificidad didáctica; enseñanza; aprendizaje; epistemología. 